\title{
Launching the Mission for 100 Climate Neutral Cities in Europe: Characteristics, Critiques, and Challenges
}

\author{
Katherine Shabb ${ }^{1}$, Kes McCormick ${ }^{1 *}$, Selma Mujkic ${ }^{2}$, Stefan Anderberg ${ }^{2}$, Jenny Palm ${ }^{1}$ \\ and Annica Carlsson ${ }^{2}$ \\ 1 International Institute for Industrial Environmental Economics, Lund University, Lund, Sweden, ${ }^{2}$ Department of \\ Environmental Technology and Management, Linköping University, Linköping, Sweden
}

OPEN ACCESS

Edited by:

Federico Cugurullo,

Trinity College Dublin, Ireland

Reviewed by:

Luisa Schmidt,

University of Lisbon, Portugal

*Correspondence:

Kes McCormick kes.mccormick@iiiee.lu.se

Specialty section:

This article was submitted to

Governance and Cities,

a section of the journal

Frontiers in Sustainable Cities

Received: 18 November 2021 Accepted: 20 December 2021

Published: 03 February 2022

Citation:

Shabb K, McCormick K, Mujkic S, Anderberg S, Palm J and Carlsson A (2022) Launching the Mission for 100

Climate Neutral Cities in Europe:

Characteristics, Critiques, and

Challenges.

Front. Sustain. Cities 3:817804. doi: 10.3389/frsc.2021.817804
The purpose of this perspective article is to critically explore the launch of the mission for 100 climate neutral cities in Europe. An overview of the mission approach in general is first presented, where key aspects and emerging critiques are identified. Second, key elements of the mission for 100 climate neutral cities in Europe are introduced along with some of its challenges and ambiguities. This perspective article ends with highlighting key emerging questions from the report " 100 Climate Neutral Cities by 2030 - by and for the citizens" where research and practice need to engage to support municipalities and urban actors in efforts on climate neutrality and help to better navigate toward radical social and technical transformation. This perspective article also proposes two approaches for inclusive participation of citizens and stakeholders that can contribute to the local implementation of the mission for 100 climate neutral cities.

Keywords: missions, innovation, cities, climate neutrality, sustainable development

\section{INTRODUCTION}

Inspired by the mission to the moon, the European Commission has adopted a mission approach to guide the Horizon Europe research and innovation framework program running from 2021 to 2027 (European Commission, 2021a). Horizon Europe aims to deliver on five main missions to solve some of the most significant challenges facing our world: adapting to climate change, cleaning up oceans, fighting cancer, creating climate neutral cities and ensuring soil health and food (European Commission, 2021b). Combined, these missions hope to push Europe forward on the European Green Deal and the Sustainable Development Goals.

The purpose of this perspective article is to critically explore the launch of the mission for 100 climate neutral cities in Europe by 2030 and suggest some ways forward to achieve this objective. The article is structured based on two research questions: What is the mission approach, its key characteristics and critiques? What is the mission for 100 climate neutral cities, and what are its ambiguities or key questions? We hope this perspective article opens up discussions and contributes to current understanding and emerging future directions to achieving 100 climate neutral cities in Europe.

Due to the novelty of the mission approach, dynamic conversations are occurring in various online forums and events. This perspective article tries to capture some of the emerging questions and critiques being discussed virtually in research and practice communities. We draw on several 
online events including: the Mission Oriented Organizations and Collaboration Models Webinar, organized by the Nordic Transition Partnership (NTP) on February 11, 2021, and the Transition Management Webinar, organized by the Network for Early Career Researchers in Sustainability Transitions (NEST) on February 18, 2021.

It is important to acknowledge that many cities in Europe and around the world have engaged in climate action for decades. It is therefore pertinent to place the mission for 100 climate neutral cities in Europe in this context. Trans-national Municipal Networks (TMNs) have also provided platforms for city-level collaboration on climate change and sustainable development. Some of the most prominent TMNs include ICLEI - Local Governments for Sustainability, C40 Cities, the Global Covenant of Mayors for Climate and Energy, and WWF Cities. These activities, initiatives and platforms have been the subject of scientific analyses in which advances and limitations have been investigated from a range of disciplinary perspectives.

\section{UNDERSTANDING THE MISSION APPROACH}

\section{Key Characteristics of the Mission Approach}

The Horizon Europe research and innovation framework program aims to deliver solutions to some of the most significant challenges facing our world. A key document in setting the foundations for the mission approach is "Governing Missions in the European Union" by Mazzucato (2019). It provides the leading definition for the mission approach in the EU context based on three key dimensions: public sector capabilities, financing mechanisms, and citizen engagement.

Mazzucato (2019, p. 2) states that: "Fundamentally, missions require putting innovation and outcomes at the center of how we think about economic growth. This requires new thinking in (1) the tools of government-from procurement to prize schemes-to drive goal-oriented experimentation; (2) the ways that public financing can crowd-in and galvanize other forms of investment; and (3) ways -to harness social movements and citizen participation in a creative, open and empowering process of challenge-led innovation."

Five criteria are further presented for selecting missions by Mazzucato (2019, p. 4). These include that missions should: "Be bold, inspirational, with wide societal relevance; Have a clear direction: targeted, measurable, and time-bound; Be ambitious but realistic research and innovation actions; $\mathrm{Be}$ cross-disciplinary, crosssectoral, and cross-actor innovation; and Drive multiple, bottom-up solutions."

In addition, Mazzucato (2018a, p. 813) argues that missions should be supported by mission-oriented policies that are "systemic public policies that draw on frontier knowledge to attain specific goals, or big science deployed to meet big problems." These characteristics lay out the basic conceptual understanding of the mission approach but leave considerable work to undertake missions in practice.

To better understand the mission approach, it is important to recognize its close connection with innovation policy. In general, innovation policy has focused on economic development and growth but it has evolved over time to focus on solving grand economic, social, and environmental challenges (Hekkert et al., 2020). Based on a brief review of documentation on the Horizon Europe research and innovation framework program and related recent publications, we have identified six key characteristics for the mission approach in the context of innovation policy. These include:

- Putting wicked problems at the core of innovation: The mission approach is presented as a "significant tool to frame innovation to solve critical problems" and provide innovation policy with a clear direction to respond to complex societal, economic and environmental challenges (Mazzucato, 2018a, p. 4).

- Creating and shaping rather than fixing markets: The mission approach encourages policy-makers to be active in creating and shaping new markets as opposed to fixing existing markets and system failures (Mazzucato, 2018a). The role of the public sector is "not just about de-risking, and leveling the playing field, but tilting the playing field in the direction of the desired goals" (Kattel and Mazzucato, 2018, p. 2).

- De-siloing governance structures: The mission approach intends to generate collaboration and planning across actors, sectors and governance scales (Mazzucato, 2017). Therefore, "public administration should evolve from its traditional silobased working culture and organization to a more strategic, cross-cutting, integrated, citizen-driven way of working" (European Commission, 2020, p. 14).

- Prioritizing participatory and bottom-up approaches: The mission approach is based on inclusive and participatory processes for citizens and stakeholders but also encourages bottom-up experimentation and learning. Mazzucato (2017, p. 6) explains that "missions may require consensus building in civil society, combining the need to set directions from above with processes of bottom-up experimentation from below".

- Positioning the state as entrepreneurial: The mission approach pushes the state and its governmental agencies to adopt an entrepreneurial approach to trigger innovation and innovative policymaking. The state is expected to shape markets, invest along the entire value chain, have equal distribution of risk and reward as the private sector as well as discover and experiment (Mazzucato, 2018b). Most importantly, an entrepreneurial state must "think big" (Mazzucato, 2015, p. 91).

- Focusing on innovation processes: The mission approach does not comprise a single innovation project, but a portfolio of projects. It is about "creating systems which allow new knowledge to diffuse across an economy and create transformative change, including increases in productivity" (Mazzucato, 2017, p. 16). 


\section{Key Critiques of the Mission Approach}

The development of the Horizon Europe research and innovation framework program has provoked debate concerning the mission approach. The critique of the mission approach focuses particularly on limitations in the perspectives in recognizing and handling the complexities of societal change processes (Wanzenböck et al., 2020; Janssen et al., 2021). Some of the main critiques about the mission approach, from the authors of this perspective article, online forums and events, as well as emerging literature, include:

- Challenges of reaching consensus: The time required to reach consensus on how to develop and implement a mission across multiple levels of government is underestimated. In addition, the challenges of trade-offs and competing interests is underplayed.

- Overestimating the role of the state: The focus on the state to lead the market transition is criticized because the role of government can be considered more of an enabler than a leader. Governance, rather than government, is presented as fundamental to societal change.

- No fundamental shifting in governance: A government can adopt a mission but tackle it with traditional policy measures by simply re-labeling policies. In that sense, missions do not necessarily require fundamentally shifting governance processes.

- Lack of a consistent systems thinking perspective: Missions can be divided into disconnected projects to be managed, which can lead to a risk of losing oversight of the overall picture and limiting the prospects of reaching ambitious goals.

- Limited understanding of complexity: The mission approach provides a one-size-fits-all solution that disregards the complexity of challenges and does not appear to recognize that societal challenges can be different in type, nature, and size.

- Simplifying participatory approaches: There appears to be insufficient understanding of the challenges and complexity of participatory engagement of citizens and stakeholders in the mission approach.

\section{LAUNCHING THE MISSION FOR 100 CLIMATE NEUTRAL CITIES}

\section{Key Characteristics of the Mission for $\mathbf{1 0 0}$ Climate Neutral Cities}

In 2019, the European Commission formed mission boards for each mission area. The objective was to advise the European Commission on the identification and implementation of missions in Horizon Europe. Mission boards were created as the result of an open call for expressions of interest, and they are expected to consult and engage with stakeholders and citizens in the process of mission design and implementation.

In 2021, the European Commission appointed mission managers to each mission to lead and coordinate activities on the missions. The mission board for the Climate Neutral and Smart Cities Mission suggested that the European Commission should establish a goal that supports and promotes 100 cities in their systemic transformation toward climate neutrality by 2030 (European Commission, 2020).

The period timeline of the 100 climate neutral cities mission consists of an early delivery phase where countries and cities set the foundations for their missions between 2020 and 2022, and the main implementation phase between 2022 and 2030. The Multiannual Financial Framework 2021-2027 and Next Generation EU will support the financing of the mission. Municipalities and urban actors, in parallel, are expected by the mission board to develop robust Climate Investment Plans, but also to take on a new role for innovation, experimentation and learning where system innovation is at the core (European Commission, 2020).

Engaging citizens in the governance of cities as key stakeholders is particularly stressed as a prerequisite for the success of the mission. In their capacities as- "users, producers, consumers or owners of building and transport means"they are considered to have the agency to transform and innovate elements of cities. A main obstacle, however, is the traditional approach to the governance of cities, characterized by sectoral division.

As a solution, three core principles of governance are identified (European Commission, 2020). These include: a holistic approach to foster innovation and development leading to integrated planning; multi-level governance where local, regional, national and European stakeholders can take part in the negotiation and networking processes around the mission; and a deep and continuous collaboration between all stakeholders facilitated through inclusive and co-creation processes.

By also taking part in the mission, each municipality is expected to create and sign a Climate City Contract (CCCs), which includes goals and targets, a strategy and action plan for transformation, with the involvement of stakeholders and their responsibilities. The CCCs are intended to be dynamic and living documents that will trigger innovation and unlock five main driving forces for transformation: new forms of participatory and innovative governance; a new economic and funding model; integrated urban planning; digital technologies; and innovation management (European Commission, 2020).

\section{Key Challenges of the Mission for 100 Climate Neutral Cities}

The report " 100 Climate Neutral Cities by 2030 - by and for the citizens" (European Commission, 2020) referred to as the report in the rest of this perspective article, is intended to outline an ambitious plan on how to achieve the mission by 2030. It describes how the mission can be accomplished with particular emphasis on the topics of governance, funding, planning, and participation. However, there are several ambiguities and challenges within the report, which the authors of this perspective article raise here to open up discussions on future directions to achieving 100 climate neutral cities in Europe.

\section{Is the Goal "Carbon Neutrality" or "Climate Neutrality"?}

The report mostly uses the term climate neutrality, however, a few times it uses the term carbon neutrality. While climate 
neutrality refers to the mitigation and offsetting of all greenhouse gas emissions, carbon neutrality refers to the mitigation of carbon dioxide only. The report states that success will be measured against carbon neutrality, yet the presented definition of carbon neutrality is in fact climate neutrality "mitigating and offsetting all greenhouse gas emissions" (European Commission, 2020). This creates the possibility for the overall objective of the mission to be misinterpreted.

\section{How to Develop and Apply "a Holistic Approach" That Can Form the Basis for Plans and for Actions for Systemic Transformation?}

A systems and holistic approach to planning is stressed in the report as the key for integrated planning and finding efficient solutions, opportunities, and synergies. Some guidance is provided on what a multi-level governance framework could look like, however, further guidance on how to implement that in practice is needed. This call for a holistic approach and systemic transformation is welcomed by the authors of this perspective article, but it demands a stronger and greater focus on how to work with climate neutrality in this way.

\section{How Should the System in Focus for the Mission Be Defined and Described?}

The report allows for different delimitations (city district, city, city agglomeration) of geographical areas as the primary focus (European Commission, 2020) but also stresses multi-level governance and vertical integration. The geographic boundaries of the cities are particularly stressed in connection with the monitoring of emissions. An overview and continuous monitoring of emissions is not only of great importance for evaluating progress that is primarily stressed in the report but should also be stressed as central for developing strategies and actions while making priorities for investments. However, to develop efficient strategies, municipalities also need sufficient knowledge and understanding of the context of different emissions, and which actors that can influence these and how.

\section{How Should the Emissions Be Monitored?}

The report states that the Global Covenant of Mayors for Climate and Energy methodology will be used to monitor progress of scope 1 (within the city) and scope 2 (electricity imports) emissions. This established methodology provides an appropriate basis for making an inventory of the most significant direct sources of emissions and some indirect emissions, but it provides no support for integrating the indirect emissions related to construction and consumption in the city, and for developing a wider understanding of the context of the emissions including key urban actors.

\section{How Are Offsets to Be Handled?}

The report states that "a maximum percentage of offsetting will be later defined since the objective of the mission is to encourage real energy efficiency, transition and transformation and not accounting of emissions." (European Commission, 2020, p. 19). It focuses, however, only on emissions, and therefore does not provide sufficient clarity for municipalities on how to integrate offsetting into their planning and monitoring framework. No explanation is provided as to how offsetting will be handled and accounted for in the mission.

\section{What Will Be the Status of Climate City Contracts?}

The mission report refers to the binding nature of the CCCs. It states that it is "not meant to be a closed document that only binds a city legally to a course of action up to 2030" (European Commission, 2020, p. 12) and then again that the CCCs will be politically binding documents (European Commission, 2020). Therefore, it is not clear whether the CCCs are legally or politically binding and to what extent. This ambiguity around the binding nature can have implications on the credibility of the process. It is critical that the CCCs are an instrument that can define the objectives, how success toward targets can be tracked, and provide a mechanism to ensure the necessary political and financial support.

\section{How Can Approaches for Inclusive Participation Be Developed in the Cities?}

Engaging citizens as key stakeholders in governance processes is particularly stressed as a prerequisite for the success of the mission toward 100 climate neutral cities. However, the report is vague on how the mission can be carried out inclusively in practice. Neither guidelines nor examples of best practices are provided. It appears to be of significant importance that inclusive participation is in focus from the design phase through to the implementation of CCCs and transformative activities by municipalities on climate neutrality.

Interestingly, the European Commission (2021c) recently published an "Info Kit for Cities" that are exploring how to participate in the mission for 100 climate neutral cities in Europe. It is a comprehensive document that delves into many of the questions posed in this perspective article and provides further practical advice to cities. However, it remains vitally important to open up discussion and critical thinking on the topics of governance, funding, planning, and participation in the context of shaping the mission approach for cities working with climate action and sustainable development.

\section{REFLECTIONS}

The launching of the five missions in Europe hopefully contribute to innovations and progress in relation to some of the most urgent challenges that the world is facing. The areas for the missions concern societal issues that can be described as wicked problems. The mission approach encourages more targeted efforts toward meeting these challenges and creating solutions. However, to successfully launch these missions, they need to be clearly defined and structured, elaborated with distinct targets within reasonable time frames, which are measurable, and they need to also be sufficiently linked to actors and realistic procedures, actions and innovations. The mission approach also needs to grapple with the complexity of these societal challenges and the interconnected nature of wicked problems.

The mission for 100 climate neutral cities in Europe is a pertinent and timely choice of mission. It is connected to 
the European Green Deal and the Sustainable Development Goals. By focusing on the city-level, this mission connects well with climate action. Many cities in Europe and around the world have not only declared ambitious goals but also developed important climate initiatives. The mission for 100 climate neutral cities can provide a new force, legitimacy and inspiration to these ongoing processes and build further on the activities and experiences of many cities. The focus on the city-level also contributes to giving the mission a context for "cross-disciplinary, cross-sectoral, and cross-actor innovation" and possibilities for driving "multiple bottom-up solutions" (Mazzucato, 2019, p. 4).

Key challenges for the mission on 100 climate neutral cities include clarifying the status of the CCCs, unifying the language around the goal concerning carbon or climate neutrality, and explaining how this is defined in terms of the delimitation of the city systems in terms of sources and sinks. The mission should also provide more detailed insights on how indirect emissions and offsets can be handled. The cities undertaking the mission will also greatly benefit from more practical guidance as how to carry out the mission in terms of applying holistic and participatory approaches in connection with the development of goals and strategies for implementing the CCCs.

Finally, this article suggests two approaches that can contribute to developing the mission for 100 climate neutral cities and provide better support to the local implementation of the mission with a focus on inclusive participation of citizens and stakeholders. First, urban metabolism (Musango et al., 2017) can provide support to defining the system in focus, handling emissions and offsets as well as identifying actors of importance in relation to the emissions. Urban metabolism conceptualizes the city as an ecosystem, analyses different resource flows and wastes connected to the city and provides a basis for combining urban planning with sustainable resource management by linking flows and actors (Anderberg, 2012). It can illustrate the essential factors and relationships behind the greenhouse gas emissions connected to the city to serve as a basis for the needed accounting tool and starting point for the strategic discussions. This can

\section{REFERENCES}

Anderberg, S. (2012). "Natural resource flows and sustainability in urban areas", in Encyclopedia of Sustainability Science and Technology, editor R. A. Meyer (New York, NY: Springer).

Bulkeley, H., and Castán Broto, V. (2013). Government by experiment? Global cities and the governing of climate change. Trans. Inst. Br. Geogr. 38, 361-375. doi: $10.1111 / \mathrm{j} .1475-5661.2012 .00535 . \mathrm{x}$

European Commission (2020). 100 Climate-Neutral Cities by 2030 - by and for the Citizens: Report of the Mission Board for Climate Neutral and Smart Cities. Brussels: Publications Office of the European Union.

European Commission (2021a). Missions in Horizon Europe. Available online at: https://ec.europa.eu/info/research-and-innovation/funding/fundingopportunities/funding-programmes-and-open-calls/horizon-europe/ missions-horizon-europe_en (accessed June 29, 2021).

European Commission (2021b). Mission Boards. Available online at: https://ec. europa.eu/info/horizon-europe/missions-horizon-europe/mission-boards_en (accessed April 22, 2021). assist cities in focusing and structuring their missions and actors to engage in change processes.

Second, urban experimentation can help provide practical entry points to implementing CCCs and support for inclusive participation. Urban living labs (ULLs) constitute a form of urban experimentation, whereby municipalities, citizens and stakeholders develop and test new (social, technical and organizational) innovation through co-creation and stakeholder engagement to address the challenges of climate change and urban sustainability (Bulkeley and Castán Broto, 2013). ULLs represent a specific form of governance, experimentation and co-creation, whereby processes of innovation, learning and engagement are formalized, and it is this that sets ULLs apart from more general policy experiments or innovation niches. For missions on climate neutral cities, urban experimentation allows testing out new innovations, technologies and policies with citizens and stakeholders under real world conditions, which can prompt radical social and technical transformation (Evans and Karvonen, 2010).

\section{DATA AVAILABILITY STATEMENT}

The original contributions presented in the study are included in the article/supplementary material, further inquiries can be directed to the corresponding author/s.

\section{AUTHOR CONTRIBUTIONS}

KS conducted the literature review and attended the online events to gather data for the article. KS and KM coordinated the writing and editing process. All authors worked together in an iterative process to develop the article and approved the final manuscript.

\section{FUNDING}

The authors acknowledge the funding from the Swedish Energy Agency for the Massive Urban Missions Project (grant number 50337-1) and the Graduate School in Energy Systems that supports the project. 
Mazzucato, M. (2015). "Building the entrepreneurial state: a new framework for envisioning and evaluating a mission-oriented public sector," in SSRN Working Paper.

Mazzucato, M. (2017). "Mission-oriented innovation policy: challenges and opportunities," in UCL Working Paper.

Mazzucato, M. (2018a). Mission-oriented innovation policies: challenges and opportunities. Indust. Corporate Change 27, 803-815. doi: 10.1093/icc/dty034

Mazzucato, M. (2018b). Mission-Oriented Research \& Innovation in the European Union: A Problem-Solving Approach to Fuel Innovation-Led Growth. Brussels: Publications Office of the European Union.

Mazzucato, M. (2019). Governing Missions in the European Union. Brussels: Publications Office of the European Union.

Musango, J. K., Currie, P., and Robinson, B. (2017). Urban Metabolism for Resource Efficient Cities: From Theory to Implementation. Paris: UN Environment.

Wanzenböck, I., Wesseling, J., Frenken, K., Hekkert, M., and Weber, M. (2020). A framework for mission-oriented innovation policy: alternative pathways through the problem-solution space. Sci. Public Policy 47, 474-489. doi: $10.1093 /$ scipol/scaa027
Conflict of Interest: The authors declare that the research was conducted in the absence of any commercial or financial relationships that could be construed as a potential conflict of interest.

Publisher's Note: All claims expressed in this article are solely those of the authors and do not necessarily represent those of their affiliated organizations, or those of the publisher, the editors and the reviewers. Any product that may be evaluated in this article, or claim that may be made by its manufacturer, is not guaranteed or endorsed by the publisher.

Copyright (c) 2022 Shabb, McCormick, Mujkic, Anderberg, Palm and Carlsson. This is an open-access article distributed under the terms of the Creative Commons Attribution License (CC BY). The use, distribution or reproduction in other forums is permitted, provided the original author(s) and the copyright owner(s) are credited and that the original publication in this journal is cited, in accordance with accepted academic practice. No use, distribution or reproduction is permitted which does not comply with these terms. 